\title{
Addressing Global Climate Change With Big Data-Driven Urban Planning Policy
}

John Zacharias, Peking University, China

\begin{abstract}
Cities in China gather data to support strategic and operational management, including databases on buildings, land use, human occupancy, underground services, and travel surveys. However, these data are seldom used to analyze policy decisions, with urban planning confined largely to operational planning. Real estate and financial interests dominate strategic planning, while an ecological crisis threatens urban sustainability in the long run. In this research, carbon emissions (CE) related to planning, building, and intra-urban travel are measured for two representative types of typical urban development in southern China, using data from Shenzhen. The two types are contemporary planned units (PUD) and dense, low-rise developments (VSD). It is found that VSD accounts for less than one-third the CE of PUD, although there is considerable diversity in the performance of PUD. Based on this research, major reductions in CE can be achieved by focussing urban planning policy on carbon-efficient development.
\end{abstract}

\section{KEYWORDS}

Carbon Emissions, China, Real Estate Development, Transport Emissions, Urban Policy

\section{INTRODUCTION}

Cities face global environmental challenges that exceed the capacities and mandates of current urban governance. Among those emerging challenges are the need to address global climate change, enhance public health, increase local food sourcing, eliminate environmental pollution, and convert to sustainable building practices, among others. In the present paper, we examine city-level intervention at the first and fifth of the major challenges listed above. The research is an investigation of the quantitative effects on carbon emissions (CE) of urban planning, using city-sourced big data and with a focus on local planned development. The intention is threefold: 1 -to investigate how globally effective measures are possible at the local urban level; 2-to gain inference about the potential for emissions reduction by scaling up urban planning policies; 3-to return urban planning to the centre of urban decision-making using proprietary urban planning data.

With regard to global climate change, China, along with 195 other state parties, signed the Paris Agreement in the context of the UNFCCC (2016) to keep average temperature to well below $2^{\circ} \mathrm{C}$ increase over pre-industrial levels. In addition to the shift to renewable energy sources, a reduction of $20 \%$ is called for in CE. China's emissions have continued to grow, however, by $1.6 \%$ in 2018 (UNEP 2019), although it is recognized that China has made significant progress toward renewable energy 
sources. Carbon emissions are intimately tied up with the way we build and move around the city. There has been a massive effort to reduce transport-based CE through new technologies, while green buildings have also become a trend. While these efforts are laudable, it is apparent that the size of the impact on CE of urban planning far exceeds that of the combined efforts in those other domains.

Sophisticated information technology (IT) systems have developed rapidly, especially in China. These include the monitoring of spatial dynamics in real time (Li, Qin et al., 2020), movement and user data from smartphones (Xing et al., 2020) and highly detailed information on underground infrastructure and geomorphology (Chen et al., 2020). Cities have invested in data-gathering on the city and by increasingly sophisticated means. Highly accurate planning bureau map databases include project plans integrated in a single database. These land use databases include information on building construction materials and public utilities at precise locations. While such data are essential to the efficient operations of the real estate market and city-provided services, they are also a source of data in urban planning. In addition, we have multiple sources for intra-urban travel. Most large cities conduct a periodic travel survey with a representative sample of residents over the entire city, including household information. Other censuses on employment, property values as well as new Internet-based sources, including Points of Interest (POI) provide other interesting databases for eventual policy development. The first two of these are reserved databases that do not circulate, for state security reasons or because of administrative barriers. They are, however, available to the planners in the planning bureaus, who are typically both client and guardian of the data. The data are often used for descriptive purposes in communications with decision-makers but, to the knowledge of this interested observer, have very rarely been used in analysis for policy development support. While there may be structural reasons for failure to exploit the potential of the data, the present focus is on their potential use after system reforms.

Urban planning education in China and in many other countries, is focussed on procedural and contractual matters within a legal framework for development approval. In China, this key role of urban planning involves transactions on leased land and the observance of requirements in the statutory plan. The statutory plan defines built-form density and land use (Liu, 2020). Details on the form of development come from other city-based regulations intended to internalize amenities such as green space, car parking, community facilities and primary schools. Urban planners at the planning bureaus and at the land management bureaus are intensively involved in these negotiations with developers, usually reacting to developer initiative and in a coordinating role with powerful city government agencies that partially fund city development and services through the development process (Zhang \& Pearlman, 2009). Other urban planners work at the planning institutes, quasi-governmental or state-owned entities that produce the plans for the developers for a fee. These two roles of urban planning place the discipline in a service role, as seen by most local governments. Arguably, that service function has grown as cities depend on the development machine to fund themselves. In the meantime, looming crises in environment, transport, and land resources, as well as the intensifying competition among cities for inward investment have made local governments pay increasing attention to the guidance of the business community, developers and state-owned actors.

Calls for the reform of urban planning to make it more effective (Liu et al., 2020) and to address the looming climate change crisis (Colding, 2017) have become insistent. Many of the planners working in the planning bureaus and institutes state that they lack the time or training or both to do what is necessary, while the urban planning schools in China continue to emphasize plan production technique. In the meantime, accurate and abundant data are assembled in database management systems.

In the present effort, we show how carbon emissions that are the result of particular urban planning practices can firstly be evaluated, with that evaluation then serving as a foundation for policy advice. While cities are characterized by an enormous range of urban forms, arrangements and building technologies, we focus on a comparison of two development types for the purposes of a comparison of their associated carbon emissions: 1-the typical gated residential community built from the mid-1990s and continuing today (xiaoqu in Mandarin) which is conventionally referred to 


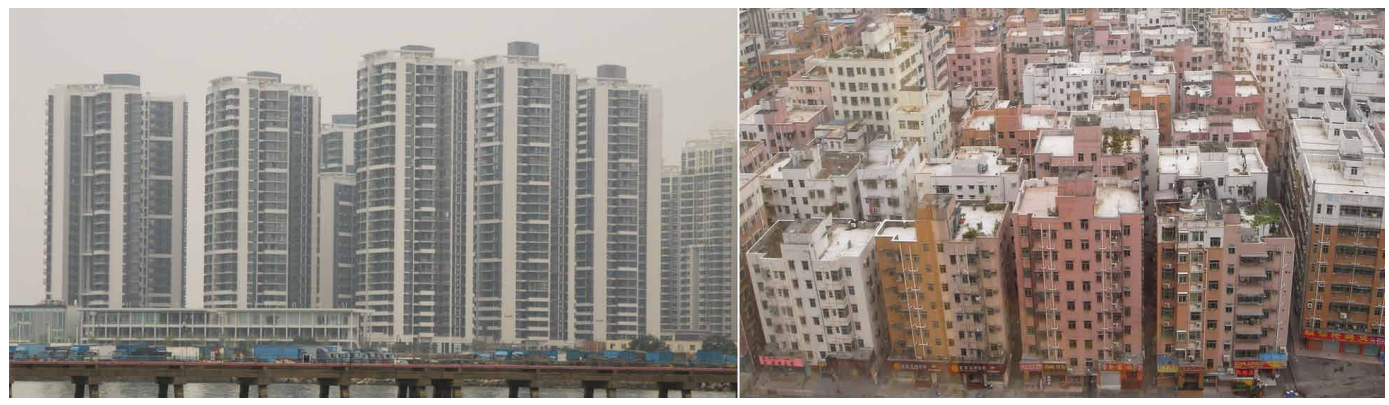

henceforth as planned unit development (PUD); 2-the rebuilt urban village within the built-up urban area (chengzhongcun), referred to henceforth as village-sponsored development (VSD). The reasons for this comparison are as follows: 1-both are primarily living habitats, which represent more than $80 \%$ of the non-industrial urban area; 2-the great majority of the existing living habitats of Shenzhen can be classified by one or other type; 3-danwei-type development or villa estates are much less prevalent and are built at lower densities than the first two types (figure 1).

In the next Literature section, we review the scientific work on carbon emissions in the building and urban transport field in the preparation of the proposed measurement model. Then Methods and Materials presents the approach and the use of the particular Shenzhen governmental databases. The sample developments are then presented. The Results section shows the total measured CE for the two types as well as variations within the samples. In Discussion, the meaning of these results is considered in terms of revised urban strategy and suggestions for further analysis. The Conclusion is a presentation of the specific results of the present study.

\section{Literature on Carbon Emissions Associated with Local Urban Development}

There is an abundant literature on CE associated with building technologies and materials as well as an increasing number of studies on the lifecycle contributions to CE. In a few rare cases (Kayaçetin and Tanyer, 2020; Lausselet et al., 2019; Wang and Zacharias, 2015), studies consider neighbourhood effects and models rather than individual buildings. In no cases, to our knowledge, are contributions from locally generated transport included with the measurements of the local buildings. In the following, we consider in order, building materials and operations technologies, building form, the urban plan at the local scale and generated transport from the local area.

The built environment accounts for a high proportion of global energy consumption, estimated at $42 \%$ in Europe according to a review by Pompani and Moncaster (2016), a rate commensurate with estimates of carbon emissions from the built environment in China (Gong and Song, 2015; Huang et al., 2017). This outcome has spurred a great deal of research into carbon mitigation in construction materials and building technique. In spite of these efforts, the traditional materials for construction has seen a steady rise in embodied carbon, with a near doubling of rates over the past 20 years (Zhao et al., 2019). In China, it is expected that the yearly amounts of CE will continue to increase with a possible peak in 2045, unless there is an unforeseen technological breakthrough or structural changes in building construction ( $\mathrm{Li}$ et al., 2020). Such growth is related to the urbanization rate in China and to the anticipated demographic decline beginning in 2023. The long lead time to emissions decline also provides great opportunity for intervention. The dependency on reinforced concrete construction has led to a depletion of the traditional sources of building sand, leading to the transport of building sand from around the world and entailing environmental damage at source. Concrete remains the favoured building material in high-rise construction, amounting to as much as $78 \%$ of all emissions during the construction phase of a building (Nasab et al., 2019). There are proposals for reducing the 
rate of growth of emissions in the use of concrete. At the design phase, choices in structural systems can result in some economies (Zhang \& Zheng, 2020). The concrete floor slab can also take a variety of forms with variable performance with regard to emissions (Paik \& Na, 2019). These structural systems and the associated materials are closely related to the building forms themselves (Thanapol \& Chavalparit, 2020; Limphitakphong et al., 2020), the uses of the buildings and by extension, to the arrangement of buildings. Additional savings are possible through off-site prefabrication of some building components and by using waste products from the processing of building materials (Teng and Pan, 2019). Previous attempts at industrialized housing have had modest success but could be more effective today, especially if building component manufacturing takes place close to the building site (Jin et al., 2020).

The research into emissions mitigation in traditional materials has flourished but so far, the projected economies will have the effect of reducing the growth of $\mathrm{CE}$, rather than reducing it in absolute terms. Alternative, low-carbon building materials have received some research attention, although more limited.

Most of the research on alternate, low-energy building materials has focussed on low-density building environments, but also suggests some application to other building environments. The use of cob construction-compacted and reinforced sub-soil-can result in reductions in global climate impacts of 75-82\% (Ben-Alon et al., 2019).

The building lifecycle is important in global emissions, especially because of demolition, site preparation and disposal of waste materials. Only a handful of studies consider the entire lifecycle of the building and especially the demolition and waste disposal stage (Yim et al., 2018). The consideration of these stages of the building lifecycle would militate in favour of building conservation and re-use. In China, the widespread practice of demolishing older buildings, even those built thirty years ago, for the development of new buildings, is a major contributor to greenhouse gas emissions. Many of those environments are reinforced structures built up at substantial density, such that demolition is a major factor in the cost and energy emissions of development. Retrofitting energy-saving features could result in up to $50 \%$ of lifecycle CE in embodied materials as well as sharp reductions in operating energy (Shirazi et al., 2020). A comparison of traditional building technique in Hangzhou and contemporary practice for a similar size building shows substantial emissions savings for the traditional building both in construction and in operation (Ding and Ying, 2019). That study estimates that it takes 18-41 years to recover the embodied energy of a traditional house when it is replaced with a contemporary structure. The use of wood structural frame buildings also shows considerable promise (Yu et al., 2011). Not only does the use of wood materials such as bamboo means we are using materials that have already extracted carbon from the atmosphere but also require less energy to erect. Several high-rise projects using wood structural frames are under development worldwide now but have required exceptions to the standard building codes.

A parallel effort to reduce emissions from the operating phase of building has demonstrated the potential in this area, as follows. The choice of operating system is important in the lifecycle energy profile of the building (Vuarnoz et al., 2018). Energy requirements for building operations have generally declined over the last 20 years, largely as a result of innovation (Röck et al., 2020). There remain substantial differences in the operating characteristics of building types, however, with hospitals using about five times the energy per unit floor area of residential buildings (Li et al., 2019). High-rise buildings can always be expected to have higher operating costs when compared with lowrise buildings. High-rises are more exposed to solar heat gain, a problem exacerbated by the recent practice in China of increasingly complex building configurations. A larger proportion of exterior wall area, with respect to floor area, adds to the cooling and heating loads. Such configurations also do not easily allow for cross-ventilation, leading to a reliance on mechanical systems. Yim et al. (2018) estimate the lifecycle emissions for their test high-rise residential building at a very high 4980 $\mathrm{kg} \mathrm{CO} 2 \mathrm{e} / \mathrm{m}^{2}$. Over the life of a building, the operating emissions can be greater than the emissions 
associated with construction, making such reduction efforts worthwhile, but innovations are largely constrained by the building type and its end use.

By building type, we could consider not only the end use but height, configuration and arrangement of buildings in plan. These considerations on operational costs lead us into the realm of urban planning. The work on area-wide CE is very limited in the literature and in very few cases (Kayaçetin \& Tanyer, 2020) includes CE for the buildings themselves. That these need to be combined should be selfevident. Higher density alone, regardless of building form, is associated with lower CE, according to a panel data study in China (Huo et al., 2020). It is already recognized that for other ecological issues, compact development is desirable, which implies higher density living habitats. Although higher density alone militates in favour of certain building forms, high-rise need not be associated with high-density. Nevertheless, high-rise forms are indirectly promoted in planning regulations in China but are often the only obvious solution to the requirements for internalizing externalities such as green space and car parking. In order to meet these planning requirements, car parking must often be constructed several metres below the green area in order for the green area to be considered as such. This implementation not only raises the amount of concrete required and excavation costs but forces the plan into disaggregated tower blocks (Zacharias et al., 2015).

As seen above with regard to building height and $\mathrm{CE}$, taller buildings require more material and more reinforcing, in particular to resist lateral loads (Mavrokapnidis et al., 2019). At higher density, such tall buildings will be arranged to optimize daylighting and views, which involves a longer building perimeter in relation to area. A higher ratio of external wall to floor area might be desirable under these conditions for the quality of the living habitat but has definite impacts on CE in embodied materials and in operations. As shown for traditional south China residential buildings, their profiles and arrangements greatly reduce solar heat gain when compared with contemporary buildings and their more spacious layouts of multiple buildings (Ding \& Ying, 2019). The space between buildings becomes very important in the carbon outcome.

Very little research has considered the CE of the landscape together with the buildings. In the Turkish example of a combined approach, it was seen that internal transport infrastructure, including car parking facilities, accounted for $25 \%$ of the total CE (Kayaçetin and Tanyer, 2020). In the case of VSD in this study, transport infrastructure is restricted to walking streets with minimal or no provisions for motor vehicles, which could then be expected to have a major impact on the CE outcome. How the landscape is treated is also important. When vegetation is abundant and tall, there are substantial declines in ambient air temperature near the ground, but also within adjacent buildings, contributing to lower energy requirements for air cooling (Wang and Zacharias, 2015). The treatment and uses of open space within a layout of buildings has direct impact on energy consumption.

The local plan is also not neutral with respect to CE from locally generated transport. Car parking provisions have already been mentioned in this respect. The facilitation of non-motorized travel within a planned area has impacts on total transport-based emissions, by increasing non-motorized trips and also connecting well with public transport. The potential inherent in planned developments has hardly been explored thus far, in part because we still lack sufficient understanding how particular measures lead to certain behaviours. While progress can be expected at this local planning scale, the rapid growth of the logistics sector with its increasing reliance on truck-based transport, is disturbing. Following the organization of the industry for the explosion of home deliveries, it is much less subject to energy-reducing technological innovations such as electrification (Huang et al., 2019).

The broad planning issues at the scale of the city need also to be considered with regard to emissions. The citywide introduction of new technologies can make a significant contribution to the reduction of CE (Newman, 2020). These might involve the general shift from private motorized travel to collective travel in low-energy vehicles or the introduction of local sources of renewable energy. In general, there are several competing approaches to local development planning from the perspective of environment. The "smart city" is criticized as having little contribution to the sustainable city (Colding \& Barthel, 2017). Building for resilience, or for conservation of land resources or for 
transport efficiency may all involve quite different planning outcomes such that future planning with $\mathrm{CE}$ as the focus should also consider the relevant outcomes if one of the above approaches is adopted.

As suggested in the above, transport-related CE is sensitive to the density, building form, layout, internal transport facilities and landscape of the local plan. While reductions in CE through technological enhancements within the existing building technologies in the above literature range up to about $10 \%$, it is expected that much higher rates can be achieved through areawide interventions. In the reviewed literature there was no study that combined CE from buildings with generated transportbased CE, perhaps because it is rare to be able to combine the relevant data sources in a single study. As is well known, CE varies enormously by transport mode (U.S. DoT, 2020), which is closely tied to the urban plan with its transport infrastructure. While the global proportion of CE in the transport sector may be on the order of 14\% (Victor et al., 2014), cities and localities may see the transport proportion rise to nearly $50 \%$. That substantial variability has much to do with the spatial structure of travel within the possibilities of the city layout (Ma et al., 2011). That great variability may be a regional or citywide characteristic but may also include high local variability. This latter point is a reason to investigate and compare contemporary habitats within the same city.

\section{Methods and Materials}

\section{Lifecycle Analysis Method}

Guidelines for building lifecycle analysis follow Müller et al. (2020). The formulae for specific EC items are adapted from Zhao et al. (2019), along with some coefficients. Nomenclature is that used by Li et al. (2013), along with some of their EC coefficients. Areawide considerations suggested by Lausselet et al., (2019) are used here. Finally, the EC estimates for various motorized transport modes are mean values derived from a large number of studies (U.S. DoT, 2020; U.S. E.P.A., 2020).

There are six components in the building sector as follows: 1-materials preparation; 2-construction; 3-operation; 4-dismantling; 5-waste disposal. The formulations follow. Transport-based CE are confined to actual operations of the study areas, calculated in annual per capita terms as for the building sector.

Eq 1-preparation of materials:

$$
C_{R B, M}=\sum_{i=1}^{n}\left(q_{i} \times G_{i}\right)=\sum_{i=1}^{n}\left(8.94 \times 10^{-5} \times q_{i} \times e_{i}\right)
$$

$i$ : constructrion material;

$n$ : number of construction materials;

$q_{i}:$ amount of type I construction material ( $\mathrm{t}, \mathrm{m} 3$, or piecer)

$G_{i}$ : carbon density of type I construction material $(\mathrm{t} / \mathrm{t}, \mathrm{t} / \mathrm{m} 3$ or $\mathrm{t} / \mathrm{piece})$

$e_{i}:$ energy density of type I construction material

$8.94 \times 10^{-5}: 1 \mathrm{MJ}$ energy emits $8.94 \times 10^{-5} \mathrm{t}$ carbon

Eq 2-construction:

$$
C_{R B, C}=\sum_{i=1}^{n}\left(q_{i} \times d_{i} \times G_{t i}\right)+\sum_{\mathrm{j}=1}^{m}\left(8.94 \times 10^{-5} \times p_{j} \times f_{i}\right)
$$

$d_{i}$ : distance between manufacturing location and building site $(\mathrm{km})$ for type $i$ construction material;

$G_{t i}: \mathrm{CE}(\mathrm{t} / \mathrm{t} \mathrm{km})$ of type $i$ construction material per unit transport distance

$p_{j}$ : quantity of type $j$ construction activity $\left(\mathrm{t}, \mathrm{m}^{3}\right.$, or $\left.\mathrm{m}^{2}\right)$ 
$f_{i}$ : energy density of type $j$ construction activity

$m$ : number of construction activity types

Eq 3-operation:

$$
C_{R B, O}=\left(0.54 \times 10^{-3} \times Q_{\text {elec }}+8.94 \times 10^{-5} \times Q_{\text {gas }}\right) \times Y
$$

$0.54 \times 10^{-3}$ : carbon density of electricity $(\mathrm{t} / \mathrm{KWh})$

$Q_{\text {elec }}$ : consumed electricity of a residential building at operation stage (KWh)

$Q_{\text {gas }}$ : consumed natural gas of a residential building at operation stage (MJ)

$Y$ : service life span of a residential building (a)

Eq 4-dismantling:

$$
C_{R B, D}=\sum_{\mathrm{k}=1}^{t}\left(8.94 \times 10^{-5} \times g_{k} \times h_{k}\right)
$$

$g_{k}$ : quantity of type $\mathrm{k}$ demolition activity $\left(\mathrm{t}, \mathrm{m}^{3}\right.$ or $\left.\mathrm{m}^{2}\right)$

$h_{k}$ : energy density of type k construction activity $\left(\mathrm{MJ} / \mathrm{t}, \mathrm{MJ} / \mathrm{m}^{3}\right.$ or $\left.\mathrm{MJ} / \mathrm{m}^{2}\right)$

t: number of demolition activity types

$\left(C_{R B^{\prime} D} \gg .9 \times C_{R B^{\prime} C}\right)$

Eq 5-waste disposal:

$$
\begin{aligned}
& C_{R B W}=\sum_{i=1}^{n}\left(W_{i} \times R_{i} \times D_{R i} \times G_{t i}\right)+\sum_{i=1}^{n}\left[W_{i}+\left(1-R_{i}\right) \times\right. \\
& \left.D_{u i} \times G_{t i}\right]
\end{aligned}
$$

$W_{i}$ : amount of type I waste $(\mathrm{t})$

$R_{i}:$ recovery ratio of type I recyclable waste $(\%)$

$D_{R i}$ : transport distance for type I recyclable $\mathrm{C} \& \mathrm{D}$ waste from building site to consumption location $(\mathrm{km})$

$D_{u i}$ : transport distance for type I unrecyclable waste from building site to disposal location $(\mathrm{km})$

\section{Data Sources}

The electronic database of urban structures in Shenzhen consists of a geo-referenced map of some 160 layers, each with distinct information at a high degree of precision. The layers of interest are of building perimeters, construction materials, height and enclosed volume. This allows us to calculate all material volumes and their associated CE, as well typical operating costs associated with classes of buildings of these types. We also calculate building floor space and population densities to reference the global resources engaged in the respective urban planning forms.

The second database is the five-year Household Travel Survey of Shenzhen, a database of about 164,000 households, with a range of socio-demographic data, including motor vehicle ownership, and the census sample of their travel destinations and modes. CE is calculated for each census individual by travel mode and distance for all individuals residing within the sample areas and annualized.

A grid of $500 \mathrm{~m}$ was laid on Shenzhen with those grid squares both adjacent to a metro station and entirely composed of residential use in either PUD or VSD retained. A sample of 149 PUD grid squares and 103 VSD grid squares were used to compare the types generally on physical development and population measures. The distributions from this sample are compared with those of the second sample, as follows. For the purposes of calculating CE, we select 10 of each of the two types of 


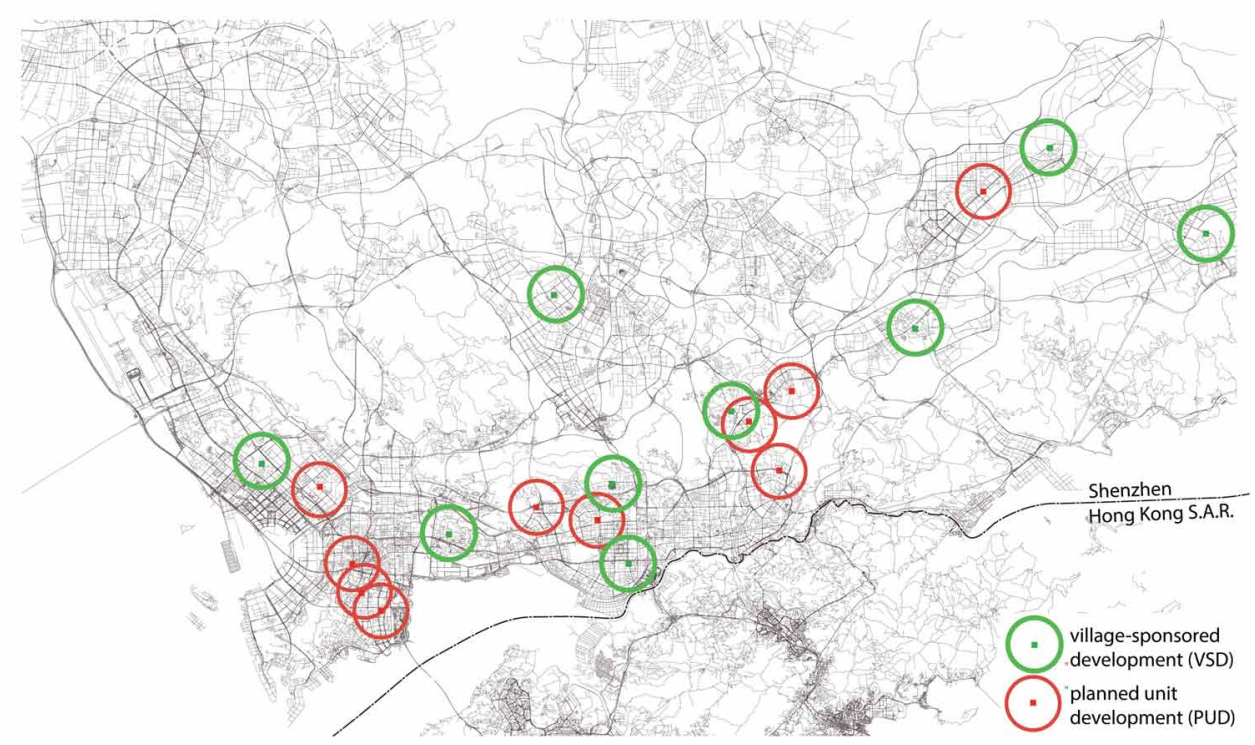

development, PUD and VSD. Half the sample was then randomly selected from within the Shenzhen Economic Zone, half from the districts to the north. They all have immediate access to rail rapid transit, to minimize the effect of this variable on the travel observations (figure 2).

\section{PUD and VSD as Urban Planning Policies}

The planned unit development (PUD) and village-sponsored development (VSD) are products of different financial, regulatory and entitlement systems, and are also physically distinct. Since the demise of the danwei or work unit and its associated housing estate in the early 1980s, the associated built form continued to be produced for another decade (Bray, 2005). The emergence of market housing, starting in 1982, like the danwei, was seen on parcels of several or many hectares, housing several thousands to several tens of thousands population. Land use and density are defined in the statutory plans (Liu et al., 2020). All such developments are on land assembled and marketed by the city in a one-time payment for a 70-year leasehold. The PUD contract is accompanied by city regulations concerning density, height, land uses, car parking standards, green space standards as well as public or community facilities.

Following the selection criteria outlined above, 20 samples were drawn from the building database, of which 8 are illustrated in Figure 3.

PUD take a variety of configurations and architectural treatments in keeping with marketing concepts. The residential buildings have between 1.1 and 2.0 parking spaces per residential unit, all provided in a subterranean slab. Ground space is given over to surface parking, internal roads and elaborate landscaping. The buildings are almost exclusively built in reinforced concrete with lifts and mechnical systems. VSD are relatively uniform in density, height and building volume. Ground space is given over almost entirely to walking streets. Shallow foundations with little or no underground space mean any car parking must occur at ground level. Arrangements may vary somewhat as a result of historical legacies or may have undergone re-adjustment to introduce a uniform grid of streets and blocks (figure 2). The typical construction system is concrete post-and-slab with masonry or brick infill. Mechanical lifts are rare as are combined mechanical systems. 
Figure 3. Building footprints are shown for some of the planned unit developments (first row) and village-sponsored developments (second row) used in the present study

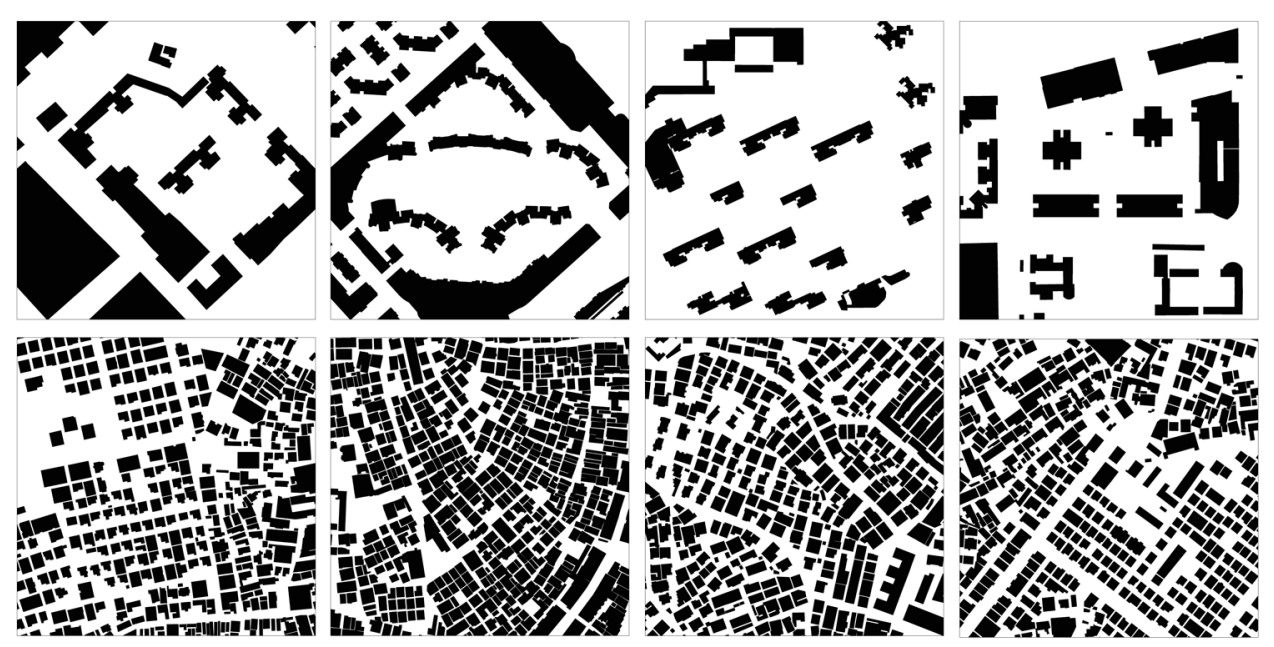

\section{Results}

A sample of 148 PUD and 103 VSD were studied for basic physical characteristics, including floorarea-ratio (FAR) and built-up proportion of the land area, along with a census of the population. These samples help validate the comparable measures for the stratified samples used to measure CE in detail, for their representativity of the whole. The FAR of PUD are nominally higher than for VSD although not significantly so (figure 4). There is more variation in the FAR among the PUD than the VSD due to design concepts but also due to the presence of more office buildings, which typically have higher FAR. Population density is significantly higher in the VSD because of smaller unit size and a higher proportion of floor space devoted to habitable space. Population density is calculated on the residential building floor space above ground, excluding the parking facilities.

Building coverage ratio is quite uniform in each of the classes of development. For VSD, the ratio is $.45(\mathrm{SD}=.82)$ while for PUD, the ratio is $.25(\mathrm{SD}=.05)$. It will be seen that coverage is highly uniform in planned development and for the reasons mentioned earlier with regard to urban planning regulations. The comparable mean figures in our samples are .48 and .29 , respectively.

The coefficients for materials cited in the literature are applied to the quantities extracted from the building database. Construction $\mathrm{CE}$ varies especially according to the height and configuration

Figure 4. The mean FAR (a) and population density (b) of VSD ( $n=103)$ and PUD ( $n=148)$, with $95 \%$ confidence bars.

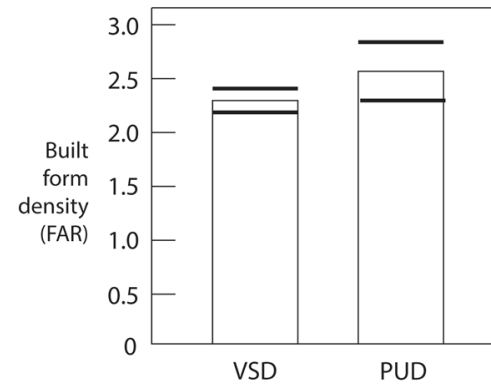

a.

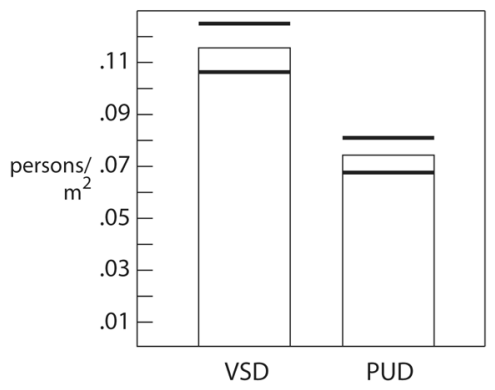

b. 
of the buildings as well as the materials, again using coefficients derived from the cited literature. While there might be debate about some of these values, they vary marginally and are in any event applied uniformly to our two samples. Building operation values are those used for recently constructed residential buildings, although some of our samples are more than ten years' old. Adjustments are made for the VSD because of the absence of central air systems and lifts, as well as less mechanical air cooling. No buildings have formal heating systems in this part of China. Transport-based emissions are scaled up from the one-day transport travel data for all motorized trips for the residential population living within the grid squares. These include trips by metro that would involve a walk from residence and also chauffeured and privately-owned cars. The figures do not include non-motorized trips, which of course have no associated CE.

The results are accumulated for each of the 6 contributing elements, 5 from the building sector and 1 from transport, with the latter unpacked later (table 1).

For ease of comparison, the summary figures in the final two columns of Table 1 are represented in the histogram of Figure 5. It will be seen that there is considerably more variation both in the building sector and in the transport sector in the PUD group.

The transport-based CE are examined in more detail with regard to the PUD and VSD. In cityplanned communities, there is substantial variation in walking and car-driving rates, but also a close relation between the two. For example, in this sample it is found that walking rates are inversely related to driving rates at $\mathrm{r}=-.40$ (figure 6). In the VSD, there is no statistical relation between walking and driving rates, but it is understood that the vast majority of such car trips would be by chauffeured car or taxi. Also, in the VSD walking rates are 50\% higher than in PUD, bicycling rates are 100\% higher, and metro use is $45 \%$ lower. With regard to the last figure it should be noted that VSD are generally farther from metro stations than the PUD. The presence of metro is an important marketing feature for new planned development, regardless of the actual level of use. In PUD, walking trips are negatively related to bus trips $(\mathrm{r}=-.55)$ and walking trips are also negatively related to metro trips $(\mathrm{r}=-.56)$. Moreover, there is a modest but significant relation between walking and cycling trips in PUD ( $\mathrm{r}=.30)$.

\section{Discussion}

Urban planning as a global project has fit uncomfortably in a neo-liberal context that favours private sector interest, more dispersed decision-making and macro-economic imperatives. The social projects of urban planning in the post-war era have been replaced with a view of the city as economic engine and of building as fixed capital. Although there are signs of improvement, in China urban planning is seen at decision-making levels as aesthetics and standardized technique, rather than as a policymaking activity for city development. This is particularly evident when one examines the results of planning competitions, where visuals dominate, and analysis plays a minor role. Important urban planning decisions, although generally confined to spatially discrete projects, are now often prepared by corporate conglomerates and engineering consultants, with the planning bureaucracy managing the approval procedures. Normative thinking and its associated prescriptions fare poorly against the claims to science of other disciplines engaged in the city-building process. This is true in contemporary China today, in ways familiar to the West, although within a decision-making framework that remains rigidly hierarchical and based in government. This author has heard from several Chinese planning officers that their advice carries less weight with time, if decision-makers are not sometimes downright skeptical. They are concerned that decisions that appear to be right for a given project or a given time, will prove damaging in the longer run and in the larger context.

The planning bureaus have exclusive access to data that would enable more policy support. The real estate development industry in China is increasingly using big data to support its plans and proposals to government and securing their position in strategic decision-making. Those data come from their own proprietary data collection systems or paid access to Internet user data and cell phone signals, for example. The data at the disposal of the planning officers is comprehensive, detailed and 
Table 1. Lifecycle carbon emissions for sample VSD and PUD, for the building sector and transport.

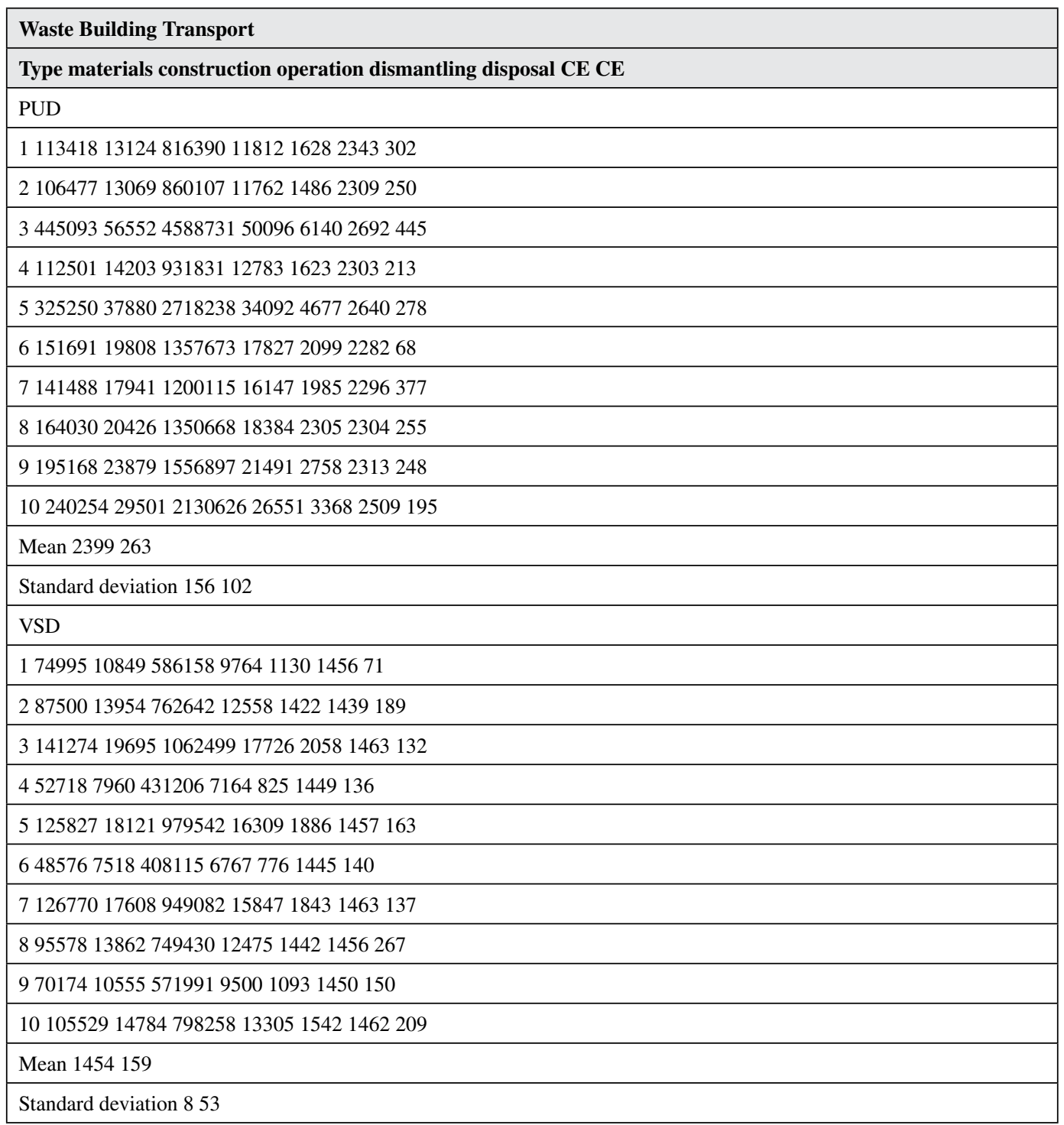

accurate, and should support policy support on the critical issues facing our cities and society in a time of unprecedented climate change.

From this study, it is clear that reforming the building system would go a long way to enabling China to meet its obligations under the UNFCCC. The specific case of urban village development is intended to illustrate the approach, rather than to treat the development as a model. It is recognized that there are problems with the village building model, but its emphasis on efficiency, conservation of materials, low operational cost and high intensity of land resource use is relevant now. Major additional reductions in building-based CE are possible by re-introducing more wood construction materials, re-using building waste and maintaining building materials production within the city.

Additional major reductions in CE are possible with a renewed shift to public transport modes and a strengthening of the role of non-motorized modes. While the technologies already exist, their 
Figure 5. Cumulative CE for the building and transport sectors for 10 PUD and 10 VSD.

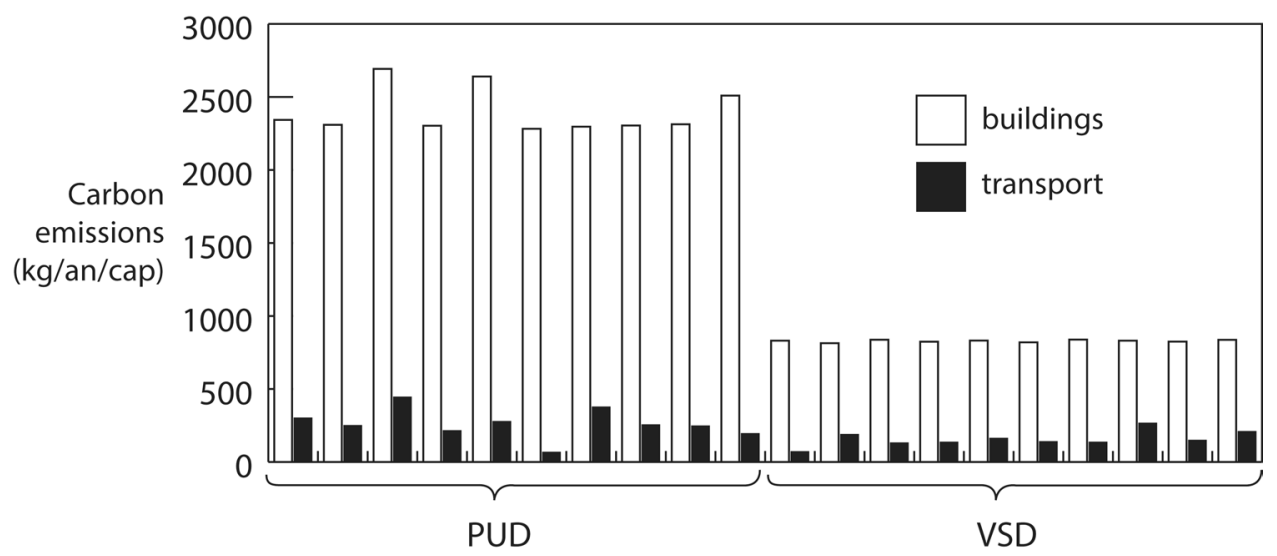

implementation with effect on $\mathrm{CE}$ requires remaking much of the road environment. For example, Newman (2020) proposes citywide carbon mitigation measures such as city-based renewable energy production and public transport innovations. In the present study, village-sponsored developments and planned developments are distributed over a contemporary road network and a fast-expanding metro system, which reduces somewhat the potential for energy-neutral transport-everyone has physical access to car transport, buses and the metro. It is clear that local urban planning form has an important impact on transport mode choice. The particular outcomes for some contemporary communities in this study point to the potential for increased levels of walking and bicycling.

Shenzhen is an ideal example because it has been in the forefront of urban innovation since its founding as a city in 1982 and now faces a situation where land resources are exhausted, the transport system is in continual crisis and the central government is investing heavily in the city as a pillar of China's next-stage economic transformation. Urban planning had a crucial and central role in the economic outcomes in those early years. Urban planning should take a leading role in enabling the new positioning of Shenzhen globally, both as an industry leader but also as a major player in the fight against climate change.

\section{CONCLUSION}

The persistent and imminent threat of climate change calls for action at the city level, where much of the problem originates. Reduction in carbon emissions in more fuel-efficient vehicles and in

Figure 6. Pedestrian and car trips in the sampled PUD in Shenzhen.

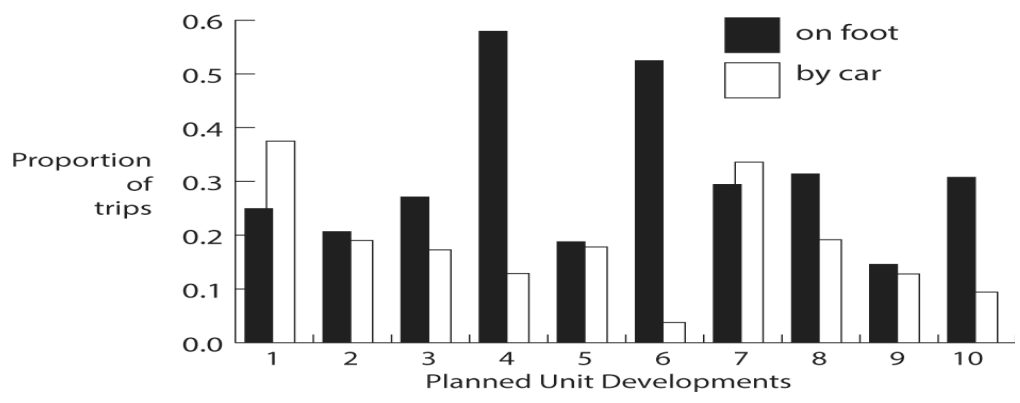


building heating, ventilation and air conditioning systems has been achieved over several years. These improvements so far do not compensate for the substantial increases in carbon emission from both intra-city travel and the building industry. Urban planning could take a critical role in addressing these two particular areas for redress, if city governments are serious about their avowed embrace of an ecologically sound future. Urban planning has traditionally been about management of urban space and its functions, sometimes with strategic intentions at the global scale. The climate crisis calls for such global approaches since it is clear that sectoral management and technological progress alone are not succeeding in the achievement of the goal of restraining ambient temperature rise.

Efforts to reduce motorized travel and to build more sustainably are ongoing, but very seldom are they combined. While we might have a sense of the direction to take in individual sectoral areas, it is more difficult to see these efforts combined in urban plans or in the management of the existing city. The elements controlled in the urban plan, including building and population density, layouts of local areas, land uses and transport systems offer enormous opportunity to reduce carbon emissions at the urban level. This potential was examined in the present study of typical development practice in the city of Shenzhen in south China. The data routinely collected by cities in China were combined in a single comparative assessment of two typical development types, to gauge the relative contributions to carbon emissions, in relatively precise fashion. It is clear that the form the development takes has considerable importance in carbon emissions. In particular, lower forms of building with associated building materials, more intensive land coverage, passive cooling and road networks that support non-motorized transport, all as currently practiced, reduce carbon emissions to about one-third of their conventional counterpart. Further intervention in building technologies could help undertake reductions in the embodied carbon of building materials, which have seen a continuous rise in recent years. The networks for movement could also be substantially reformed for the same purpose. The quantitative assessment of the benefits of these urban planning measures, it is hoped, can solidify the urban planning role in urban policymaking. 


\section{REFERENCES}

Ben-Alon, L., Loftness, V., Harries, K. A., DiPietro, G., \& Hameen, E. C. (2019). Cradle to site Life Cycle Assessment (LCA) of natural vs conventional building materials: A case study on cob earthen material. Building and Environment, 160, 106150. doi:10.1016/j.buildenv.2019.05.028

Bray, D. (2005). Social space and governance in urban China - the Danwei System from origins to Reform. Stanford University Press.

Chen, L., Shi, P., Tang, Q., Liu, W., \& Wu, Q. (2020). Development and application of a specification-compliant highway tunnel facility management system based on BIM. Tunnelling and Underground Space Technology, 97, 103262. doi:10.1016/j.tust.2019.103262

Colding, J., \& Barthel, S. (2017). An urban ecology critique on the "Smart City" model. Journal of Cleaner Production, 164, 95-101. doi:10.1016/j.jclepro.2017.06.191

Ding, G., \& Ying, X. (2019). Embodied and operating energy assessment of existing buildings - demolish or rebuild. Energy, 182, 623-631. doi:10.1016/j.energy.2019.06.056

Gong, Y., \& Song, D. (2015). Life cycle building carbon emissions assessment and driving factors decomposition. Analysis based on LMDI-A case study of Wuhan City in China. Sustainability, 7(12), 16670-16685. doi:10.3390/ su71215838

Huang, B., Xing, K., \& Pullen, S. (2017). Carbon assessment for urban precincts: Integrated model and case studies. Energy and Building, 153, 111-125. doi:10.1016/j.enbuild.2017.07.087

Huang, Y., Liao, C., Zhang, J., Guo, H., Zhou, N., \& Zhao, D. (2019). Exploring potential pathways towards urban greenhouse gas peaks: A case study of Guangzhou, China. Applied Energy, 251, 113369. doi:10.1016/j. apenergy.2019.113369

Huo, T., Li, X., Cai, W., Zuo, J., Jia, F., \& Wei, H. (2020). Exploring the impact of urbanization on urban building carbon emissions in China: Evidence from a provincial panel data model. Sustainable Cities and Society, 56, 102068. doi:10.1016/j.scs.2020.102068

Jin, R., Hong, J., \& Zuo, J. (2020). Environmental performance of off-site constructed facilities; a critical review. Energy and Building, 207, 109567. doi:10.1016/j.enbuild.2019.109567

Kayaçetin, N. C., \& Tanyer, A. M. (2020). Embodied carbon assessment of residential housing at urban scale. Renewable \& Sustainable Energy Reviews, 117, 109470. doi:10.1016/j.rser.2019.109470

Lausselet, C., Ellingsen, A.-W., Linda, H. S., \& Brattebø, H. (2019). A life-cycle assessment model for zerio emission neighborhoods. Journal of Industrial Ecology, 24(3), 500-516. doi:10.1111/jiec.12960

Li, B., Han, S., Wang, Y., Wang, Y., Li, J., \& Wang, Y. (2020). Feasibility assessment of the carbon emissions peak in China's construction industry: Factor decomposition and peak forecast. The Science of the Total Environment, 706, 135716. doi:10.1016/j.scitotenv.2019.135716 PMID:31831236

Li, D., Qin, B., Liu, W., \& Deng, L. (2020). A city monitoring system based on real-time communication interaction module and intelligent visual information collection system. Neural Processing Letters. Advance online publication. doi:10.1007/s11063-020-10325-5

Li, D. Z., Chen, H. X., Hui, E. C. M., Zhang, J. B., \& Li, Q. M. (2013). A methodology for estimating the life-cycle carbon efficiency of a residential building. Building and Environment, 59, 448-455. doi:10.1016/j. buildenv.2012.09.012

Li, H., Deng, Q., Zhang, J., Xia, B., \& Skitmore, M. (2019). Assessing the life cycle $\mathrm{CO}_{2}$ emissions of reinforced concrete structures: Four cases from China. Journal of Cleaner Production, 210, 1496-1506. doi:10.1016/j. jclepro.2018.11.102

Lim, D-B., Son, S., Kim, S., \& Park, J. (2019). Life cycle cost and CO2 emission simulation models of apartment building proejcts using system dynamics. Indoor and Built Environment, 28(3), 310-321. $10.1177 / 1420326$ X18754342 
Limphitakphong, N., Thaipradit, P., Kanchanapiya, P., Tantisattayakul, T., \& Chavalparit, O. (2020). Embodied carbon emissions of construction materials: A case study of buildings in Thailand. International Journal of GEOMATE, 18(68), 187-193. doi:10.21660/2020.68.9418

Liu, T., Huang, D., Tan, X., \& Kong, F. (2020). Planning consistency and implementation in urbanizing China: Comparing urban and land use plans in suburban Beijing. Land Use Policy, 94, 104498. doi:10.1016/j. landusepol.2020.104498

Liu, T., Huang, D., Xin, T., \& Kong, F. (2020). Planning consistency and implementation in urbanizing China: Comparing urban and land use plans in suburban Beijing. Land Use Policy, 104498, 104498. Advance online publication. doi:10.1016/j.landusepol.2020.104498

Ma, J., Chai, Y., \& Liu, Z. (2011). The impact mechanism of Beijing's traffic carbon emissions based on residents' travel behavior. Acta Geographica Sinica, 66(8), 1023-1032.

Mavrokapnidis, D., Mitropoulou, C. C., \& Lagaros, N. D. (2019). Environmental assessment of cost optimized structural systems in tall buildings. Journal of Building Engineering, 24, 100730. doi:10.1016/j.jobe.2019.100730

Müller, L. J., Kätelhön, A., Bachmann, M., Zimmermann, A., Sternberg, A., \& Bardow, A. (2020). A guideline for life cycle assessment of carbon capture and utilization. Frontiers in Energy Research, 8, 15. doi:10.3389/ fenrg.2020.00015

Nasab, T. J., Monavari, S.M., \& Jozi, S.A. (2019). Assessment of carbon footprint in the construction phase of high-rise constructions in Tehran. International Journal of Environmental Science and Technology.

Newman, P. (2020). Cool planning: how urban planning can mainstream responses to climate change. Cities, 103.

Newman, P. (2020). Cool planning: How urban planning can mainstream responses to climate change. Cities (London, England), 103, 102651. doi:10.1016/j.cities.2020.102651

Paik, I., \& Na, S. (2019). Evaluation of carbon dioxide emissions amongst alternative slab systems during the construction phase in a building project. Applied Sciences (Basel, Switzerland), 9(20), 4333. doi:10.3390/ app9204333

Pomponi, F., \& Moncaster, A. (2016). Embodied carbon mitigation and reduction in the built environment-What does the evidence say? Journal of Environmental Management, 181, 687-700. doi:10.1016/j.jenvman.2016.08.036 PMID:27558830

Röck, M., Saade, R. M., Marcella, B., Maria, N. R., \& Freja, B. (2020). Embodied GHG emissions of buildings - The hidden chellenge for effective climate change mitigation. Applied Energy, 258, 114107. doi:10.1016/j. apenergy.2019.114107

Shirazi, A., \& Ashuri, B. (2020). Embodied Life Cycle Assessment (LCA) comparison of residential building retrofit measures in Atlanta. Building and Environment, 171, 106644. doi:10.1016/j.buildenv.2020.106644

Teng, Y., \& Pan, W. (2019). Systematic embodied carbon assessment and reduction of prefabricated highrise public residential buildings in Hong Kong. Journal of Cleaner Production, 238, 117791. doi:10.1016/j. jclepro.2019.117791

UNEP. (n.d.). Emissions Gap Report 2019. Global progress report on climate action. United Nations Environmental Programme.

United Nations Framework Convention on Climate Change. (2016). United Nations Treaty Collection. https:// treaties.un.org/Pages/ViewDetails.aspx?src=TREATY\&mtdsg_no=XXVII-7-c

United States Department of Transportation. (2010). Public transportation's role in responding to climate change. www.transit.dot.gov

United States Environmental Protection Agency. (2020). Greenhouse gas emissions from a typical passenger vehicle. https://222.epa.gov/greenvehicles/greenhouse-gas-emissions-typical-passenger

Victor, D. G., Zhou, D., Ahmed, E. H. M., Dadhich, P. K., Olivier, J. G. J., Rogner, H.-H., . . Yamaguchi, M. (2014). Introductory chapter. In Climate change 2014: Mitigation of climate change. Contribution of working group III to the fifth assessment report of the intergovernmental panel on climate change. Geneva, Switzerland: Intergovernmental Panel on Climate Change. 
Vuarnoz, D., Cozza, S., Jusselme, T., Magnin, G., Schafter, T., Couty, P., \& Niederhauser, E.-L. (2018). Integrating hourly life-cycle energy and carbon emissions of energy supply in buildings. Sustainable Cities and Society, 43, 305-316. doi:10.1016/j.scs.2018.08.026

Wang, Y., \& Zacharias, J. (2015). Landscape modification for ambient environmental improvement in Central Business Districts-a case from Beijing. Urban Forestry \& Urban Greening, 14(1), 8-18. doi:10.1016/j. ufug.2014.11.005

Xing, Y., Wang, K., \& Lu, J. J. (2020). Exploring travel patterns and trip purposes of dockless bike-sharing by analyzing massive bike-sharing data in Shanghai, China. Journal of Transport Geography, 87, 102787. doi:10.1016/j.jtrangeo.2020.102787

$\mathrm{Xu}$, B., Zhou, S., \& Hao, L. (2015). Approach and practices of district energy planning to achieve low carbon outcomes in China. Energy Policy, 83, 109-122. doi:10.1016/j.enpol.2015.04.008

Yim, S. Y. C., Ng, S., Hossain, M., \& Wong, J. (2018). Comprehensive evaluation of carbon emissions for the development of high-rise residential building. Buildings, 8(11), 147. doi:10.3390/buildings8110147

Yu, D., Tan, H., \& Ruan, Y. (2011). A future bamboo-structure residential building prototype in China: Life cycle assessment of energy use and carbon emission. Energy and Building, 43(10), 2638-2646. doi:10.1016/j. enbuild.2011.06.013

Zacharias, J., Sun, Z., Chuang, L., \& Lee, F. (2015). The hutong development model compared with contemporary suburban development in Beijing. Habitat International, 49, 260-265. doi:10.1016/j.habitatint.2015.05.035

Zhang, S., \& Pearlman, K. (2009). Legislative support for urban land-use control in China. Environment and Planning. C, Government \& Policy, 27(3), 399-412. doi:10.1068/c0774b

Zhang, X., \& Zheng, R. (2020). Reducing building embodied emissions in the design phase: A comparative study on structural alternatives. Journal of Cleaner Production, 243, 118656. doi:10.1016/j.jclepro.2019.118656

Zhao, S., Song, Q., Duan, H., Wen, Z., \& Wang, C. (2019). Uncovering the lifecycle GHG emissions and its reduction opportunities from the urban buildings: A case study of Macau. Resources, Conservation and Recycling, 147, 214-226. doi:10.1016/j.resconrec.2019.04.030

John Zacharias is Chair Professor and Director of the Laboratory on Urban Process Modelling and Applications since 2012. Prior to the present appointment he was Professor at Concordia University's Department of Geography, Planning and Environment. His work is in human response to the built environment at all scales in urban settings. Recent work uses big data to understand non-motorized urban travel. 